\title{
Consumption of psychotropic medicines at a referral hospital in Namibia: findings and implications
}

\author{
Maria N Kafula ${ }^{1}$, Emmanuel Ugburo ${ }^{2}$, Dan Kibuule ${ }^{1}$
}

\begin{abstract}
1. School of Pharmacy, Faculty of Health Sciences, University of Namibia, Windhoek Namibia; mntk26@gmail.com

2. Intermediate Katutura Hospital, Windhoek, Namibia.
\end{abstract}

\begin{abstract}
Setting: In Namibia, the burden of mental illnesses is estimated at $25.6 \%$ and is expected to double by 2025 . Few studies in sub-Saharan Africa estimate the consumption rates of psychotropic medicines as a proxy of irrational use.

Aim: The consumption rate of psychotropic medicines at a referral hospital was determined.

Method: A hospital-based retrospective medicine utilization analysis of Facility Electronic Stock Card (FESC) psychotropic medication was conducted at Intermediate Hospital Katutura over a 7 year period, 2011-2017. Data on consumption and expenditure on psychotropic medicines were abstracted from FESC and analysed using descriptive statistics in SPSS v22. The main outcomes were consumption rates, daily Defined Dose, (DDD) and/or expenditure.

Results: Of the 580351,4 DDD of psychotropic medicines consumed, $84 \%$ were anti-psychotics, $9.2 \%$ anti-depressants and $6.8 \%$ anxiolytics. Anti-psychotics (48.8\%) and anxiolytics (47.9\%) had the highest consumption by cost relative to antidepressants (3.3\%). The most consumed antidepressants were imipramine (62\%) by DDD and fluoxetine (55.8\%) by cost. The most consumed anti-psychotics were chlorpromazine (74.6\%) by DDD and haloperidol (68.4\%) by cost respectively. Diazepam (79.4\%) and hydroxyzine (94.2\%) were most consumed sedative-hypnotics by DDD and cost respectively.

Conclusion: The consumption of new psychotropics contributes to higher costs. There is need for cost-effectiveness analysis of new versus conventional psychotropics to optimize treatment, outcomes and costs.
\end{abstract}

Keywords: Pyschotropics, consumption rate, DDD, Namibia.

DOI: https://doi.org/10.4314/ahs.v20i2.57

Cite as: Kafula MN, Ugburo E, Kibuule D. Consumption of psychotropic medicines at a referral hospital Namibia: findings and implications. Afri Health Sci. 2020; 20(2): 1000-1010. bttps:// doi.org/10.4314/abs.v20i2.57

\section{Introduction}

Mental and behavioral disorders such as depression, schizophrenia and anxiety disorders are prevalent worldwide ${ }^{1-6}$ and are an increasing public health burden Namibia ${ }^{7}$. The World health organization (WHO) estimates that mental illnesses account for $12 \%$ of the global burden of disease in comparison to malaria, tuberculosis, and HIV/AIDS which together account for $8.2 \% .8,9$ Moreover, the prevalence of mental illnesses among adults (i.e. above 18 years) globally is estimated

\section{Corresponding author: \\ Dan Kibuule, \\ Department of Pharmacy Practice and Policy, \\ School of Pharmacy, University of Namibia, \\ P.O.Box 13301, Pioneers Park, and Windhoek, Namibia. \\ Tel: +264(0)816280835 \\ Email:dkibuule@unam.na}

at $10 \% .{ }^{10}$ The public health burden is greatest among low and middle-income countries such as Namibia. In Namibia, the prevalence of mental illnesses is estimated at $25.6 \%{ }^{11}$ and is expected to double by 2025 . The main drivers of mental illnesses in Namibia have been attributed to abuse of illicit drugs and alcohol, chronic infections as well as socio-economic factors among others ${ }^{7}$. The main intervention to reduce the burden of mental illnesses globally and in Namibia is the integration in mental health care in primary health care. ${ }^{12}$ However, the main barrier to inequitable access to mental services in these countries, is limited health workforce, i.e. psychiatrists and mental health nurses as well as skills transfer ${ }^{13,14}$. In Namibia, the universal access to mental health care services such as pharmacotherapy, psychotherapy and psychosocial rehabilitation, among others has significant improved the quality of care for the mentally ill ${ }^{15-17}$. Nevertheless the use of psychotropics (i.e. antipsychotics, antidepressants, mood stabilizers 
and sedative-hypnotics have been associated with adverse effects, poor medication compliance, heath care financial burden ${ }^{18}$ and interference with normal functioning ${ }^{19}$. Recently there has been conflicting data on the benefits and/or effectiveness of antidepressants ${ }^{20-23}$ and sedative-hypnotics ${ }^{24}$ yet they remain widely used in Namibia. This is a concern as it exposes patients to ineffective treatments at leads to poor outcomes and drains the health care budgets in these resource constrained LMIC?

In addition the development of new psychotropic (i.e. medicines used to treat symptoms of mental disorders) agents in last decades, such as atypical antipsychotics (e.g. clozapine and quetiapine), and Selective Serotonin Reuptake Inhibitors (SSRIs, e.g. fluoxetine and paroxetine), has led to better disease prognosis and increased $\operatorname{costs}^{19}$. There are increasing shift towards the use of antipsychotics based on a continuum of potential adverse effects rather than atypical or typical classifications $^{25}$. Nonetheless, increased burden of mental illness and integration of new psychotropics in the essential medicines lists of Namibia has been paralleled with increased expenditure on mental health care to the already resource-constrained governments in $\mathrm{LMIC}^{19}$. The expenditure on psychotropic medication may be reduced by use of generic that have become readily available at reduced costs ${ }^{26}$.

Consequently, the aim of the study was assess the consumption of psychotropic medicine in public health care at a national referral hospital in Namibia. This will provide preliminary benchmark on the trend on consumption os psychiatric medication as a proxy to assessment of their rational use to guide strategic planning for the public health sector.

\section{Methods and Materials \\ Study design and population}

A facility-based retrospective medicine utilization anlaysis determined the rates of consumption of psychotropic medication at Windhoek's regional referral hospital, Katutura State Hospital, Windhoek. The target population included all medicine stock records (i.e. the Facility Electronic Stock Cards, FESC) for psychotropic medications. The accessible population were consumption data on psychotropic medication, ordered and issued from the main pharmacy of Katutura hospital to in-patient and outpatient units of the hospital for the review period 2011-2017. The study only included psychotropic medicines recommended for use in the Namibia essential medicine list $(\mathrm{Nemlist})^{27}$ and the $\mathrm{Na}$ - mibia Standard Treatment Guidelines (NSTG) ${ }^{28}$ as the main reference document for psychotropic medicines used at public health facilities. The main study variables were the psychotropic medication, dosage/units dispensed as well as the dosage formulations. The study excluded records with missing data on the main outcome, i.e. consumption by dose ordered or issued ( $\mathrm{mg}$ ) and/or price.

\section{Mental Health Program in Namibia}

The National Mental Health Program for Namibia is implemented under the Disability Prevention and Rehabilitation Division in the Primary Health Care Directorate of the Ministry of Health and Social Services. The program was launched in 1995 with the responsibility to promote mental health, prevent mental disorders, treat and rehabilitate affected individuals and families and aims to improve the standard of mental health care through a comprehensive Mental Health Care services and building of the capacity on mental health of all health care providers as well as the introduction of a strong community based mental health care program. The mental health program is currently headed by a qualified psychiatric nurse. In addition, the mental health programme is mandated to foster policy formulation, strategic planning, technical support to all levels, implementation, monitoring and evaluation of the mental health activities including planning for human resource training.

Specialized mental health services in Namibia are currently accessible at Windhoek Mental Health Care Centre (i.e. the national referral hospital), in form of outpatient and inpatient services to adults and children, with a civil psychiatry bed capacity of one hundred and twenty four beds (124); The Forensic psychiatric Service, located in the same Centre and has eighty four (84) beds, and an outpatient clinic that provides service to a minimum of 45 patients on Monday and Wednesdays, and; The Oshakati Psychiatric Unit in Oshakati intermediate Hospital which serves Oshana, Oshikoto, Omusati and Ohangwena regions, with a bed capacity of 80 beds, but admits up to ninety (90) patients per day, and a large outpatient clinic that provides service to a minimum of 100 patients per day. Altogether, the units have 173 range of professionals.

The Pharmaceutical Management information system (PMIS) of the hospital estimates that over 500 units (tablets, capsules, injectables) of psychotropics are dispensed every year at the facility. 


\section{Data collection procedures}

Data on the type of psychotropic medication, amount ordered or issue ( $\mathrm{mg}$, i.e. milligram) and cost $(\mathrm{N} \$$, i.e. Namibian dollars) were abstracted from the Facility Electronic Stock Card (FESC) using an abstraction tool (Appendix A). The FESC is a desktop software that assists proper maintenance and monitoring of stock position and automated reporting to the MoHSS Pharmaceutical Information Dashboard introduced in 2015. FESC allows health facilities to effectively monitor stock level of essential commodities, stock taking, ordering and monthly stock reporting. In addition, FESC has option to upload monthly stock report and order book to dashboard, and this data can be used by regional warehouses for order for supply. The data abstraction tool was pre-tested and validated on two psychotropic drugs (i.e.Diazepam and Lorazepam) at Intermediate Hospital Katutura. The data were collected retrospectively (2011-2017) by the researcher (MK) over a three-month period, February-April 2018 at the Katutura Hospital Main Pharmacy. The data were subsequently validated by the research team (MK, DK and EU) for accuracy and completeness against the manual stock cards.

\section{Data analysis}

The collected data were entered in Epidata v3.1 for management (i.e. screening for errors, missing data and sorting in classes by antipsychotic drug). The main outcomes were the consumption of psychotropic medicines by Daily Defined Dose (i.e. DDD, that refers to the assumed average maintenance dose in $\mathrm{mg}$ per day for a drug used for its main indication in adults for each psychotic medicine) and price in Namibian dollars ( $N \$$ ) for the six-year period, 2011-2017. The covariates were the classes of and dosage forms of the psychotropic drugs. Data was then exported to SPSS v22 for quantitative statistical analysis. The World health organization Anatomical Therapeutic Chemical/ Daily defined $\operatorname{Dose}^{29,30}$ (WHO-ATC/DDD, i.e. a standardized system for reporting on consumption of medicines world-wide in order to improve drug quality use) Classification System was then employed to calculate the drugs defined doses for each psychotropic medicine. Subsequently, the total DDD consumption per class of psychotropic was determined as well as for each individual drug comprised in the class. The same procedure was replicated for consumption by cost of the medicines and class. We did not include any denominator as only targeted use in one mntal health care center was conducted.

\section{Ethical considerations}

Ethical approval was granted by the institutional review boards of the Faculty of Health Sciences, University of Namibia, Ministry of Health and Social Services and Katutura Intermediate Hospital. The requirement for consent was waivered by the review boards as the study did not directly deal with human subjects or their records. In no way did the study do any harm and did not pose any form of threat to the people, community or the country at large. Nonetheless all data were not shared to a third party unless directly involved in the study. The data collected contained in an encrypted device and only be accessible to a limited number of people who are involved in the research.

\section{Results \\ Consumption of psychotropic classes by DDD and Cost}

Table 1 demonstrates the consumption of psychotropic classes by total DDD and expenditure $(\mathrm{N} \$)$. Of the three (3) classes of psychotropic (i.e. anti-psychotics, antidepressants and sedative-hypnotics) medication, 580351.4 DDDs were consumed over the seven-year period. The consumption by DDDs was highest with antipsychotics (84\%) compared to antidepressants $(9.2 \%)$ and sedative-hypnotics $(3.3 \%)$. The expenditure associated consumption for all psychotropic medication over the seven-year period was $\mathrm{N} \$ 1613287.52$. The expenditure $(\mathrm{N} \$)$ was highest with antipsychotics $(48.8 \%)$, followed by anxiolytics (47.9\%), then antidepressants $(3.3 \%)$ (Table 1$)$.

Figure1 shows the consumption of psycholeptics class by DDD and Cost, and Figure 2 shows percentage consumption of psycholeptics class by DDD and Cost, according to Table 1. 
Table 1: Consumption of psycholeptics classes by DDD and Cost

\begin{tabular}{lll}
\hline $\begin{array}{l}\text { Psychotropics } \\
\text { (WHO/ATC class) }\end{array}$ & $\begin{array}{l}\text { Consumption Rates } \\
\text { DDD (mg/day, \%) }\end{array}$ & Cost $(\mathrm{N} \$, \%)$ \\
\hline All classes & $580351.4(100)$ & $1,613,287.52(100)$ \\
\hline $\begin{array}{l}\text { Antidepressants } \\
\text { (ATC N06A) }\end{array}$ & $53242.9(9.2)$ & $53,222.16(3.3)$ \\
\hline $\begin{array}{l}\text { Antipsychotic medicines } \\
\text { (ATC N05A) }\end{array}$ & $487445.8(84)$ & $787,406.30(48.8)$ \\
\hline $\begin{array}{l}\text { Anxiolytic medicines } \\
\text { (ATC N05B) }\end{array}$ & $39662.7(6.8)$ & $772,659.10(47.9)$ \\
\hline
\end{tabular}

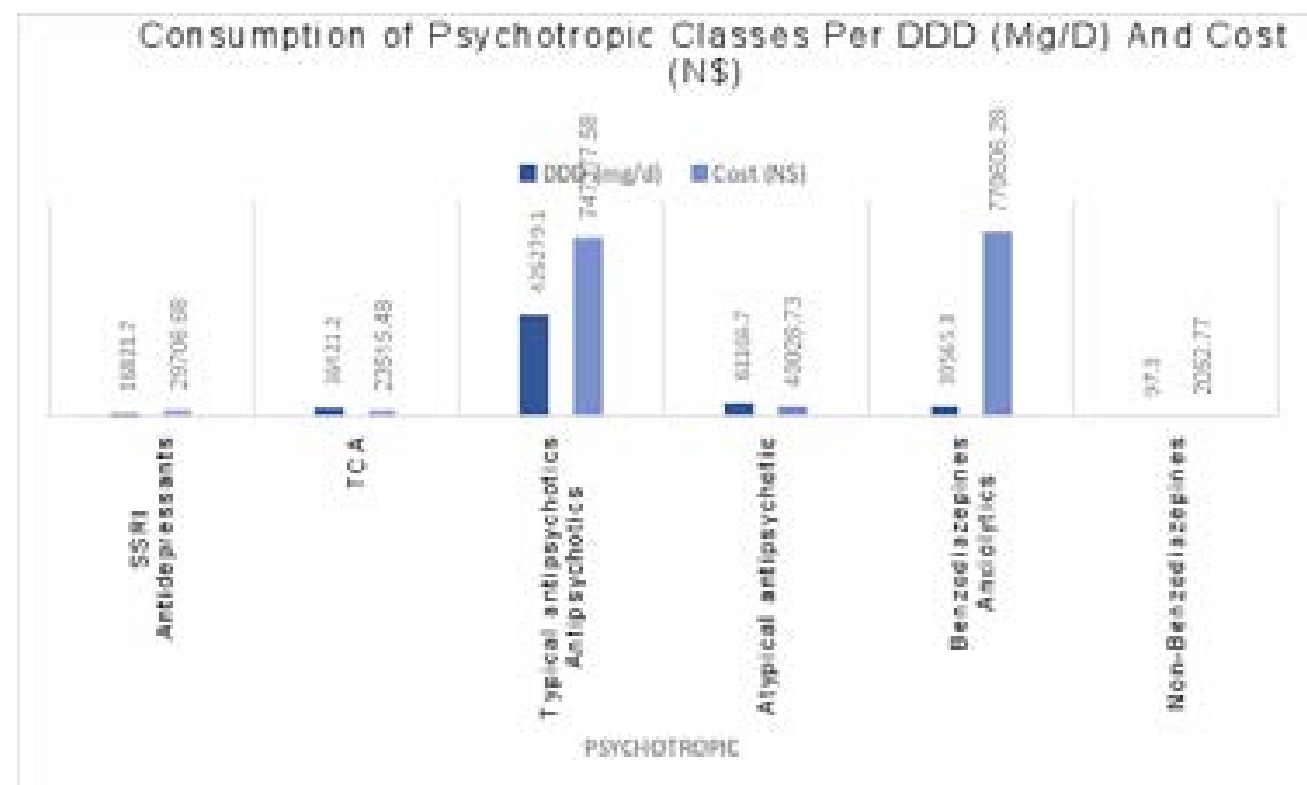

Figure 1: Consumption of psycholeptics class by DDD and Cost

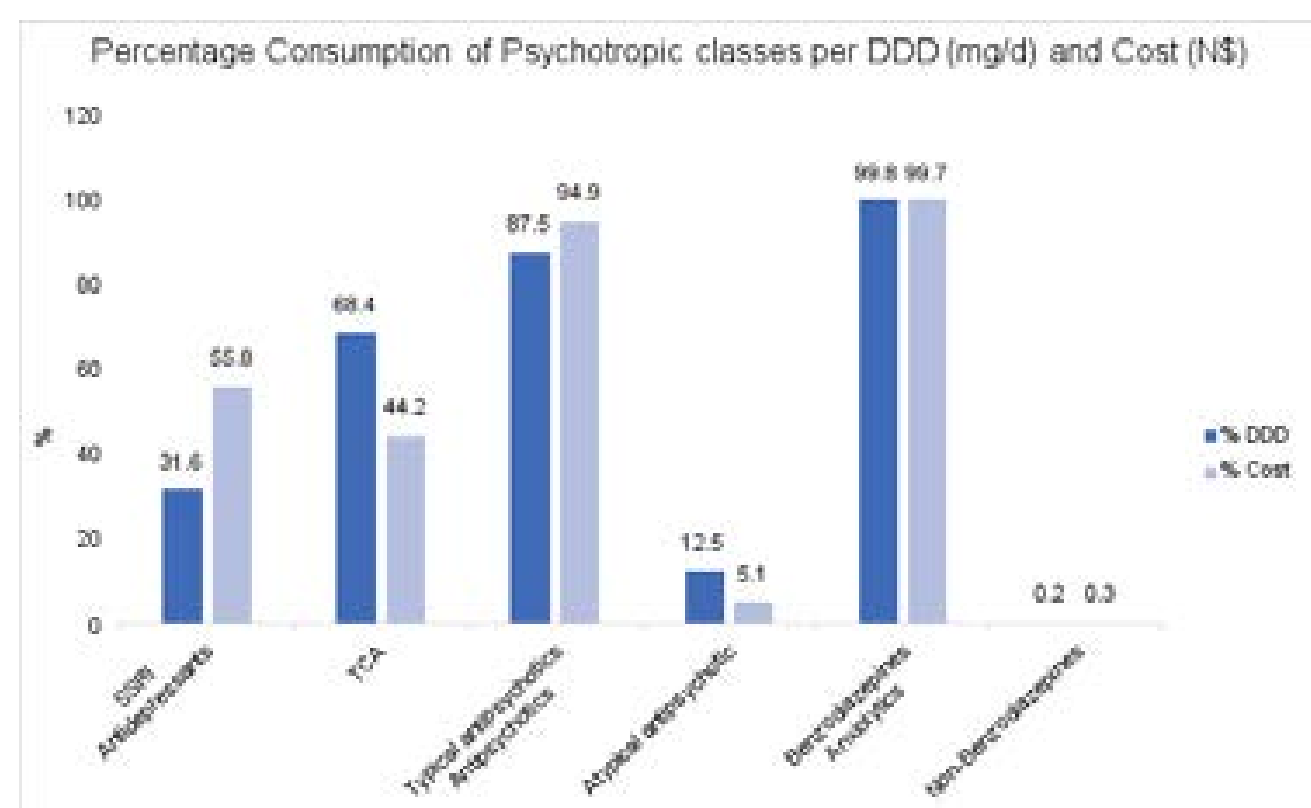

Figure 2: Percentage consumption of psycholeptics class by DDD and Cost 
Consumption of psychotropic agent by DDD and Cost

Table 2 consist of consumption of psycholeptics by DDD and Cost of the individual drugs per class. Among antidepressants, TCA had the highest DDD consumption of $68.4 \%$ than SSRI $(31.6 \%)$. By cost, SSRI had the highest consumption $(55.8 \%)$ then the TCA with $44.2 \%$. imipramine was the highly consumed $(62 \%)$ by DDD, followed by fluoxetine $(51.0 \%)$ and amitriptyline $(6.4 \%)$. Fluoxetine was the most highly consumed by price $(55.8 \%)$, then amitriptyline $(41.2 \%)$ and lastly imipramine $(3.0 \%)$.

Of the antipsychotics, typical anti-psychotics consumed $87.5 \%$ DDD while the atypical, $12.5 \%$. Cost consumption was also high with typical anti-psychotics (94.9\%) than the atypical antipsychotics (5.1\%). With the typical anti-psychotics, highly consumed DDD was seen with chlorpromazine $(74.6 \%)$, with the lowest DDD consumption being $0.00016 \%$ of Chlorpromazine. The rest of the typical antipsychotic drugs showed a DDD consumption of less than $10 \%$ (droperidol (0.6\%), fluphenazine $(0.1 \%)$, flupenthixol $(0.4 \%)$, haloperidol $(9.2 \%)$, thioridazine $(2.4 \%)$, zuclopenthixol acetate $(0.017 \%))$. Haloperidol took up the most cost of $68.4 \%$ compared to other typical antipsychotic drugs and thioridazine being the least consumed $(0.2 \%)$. The atypical antipsychotics, sulpiride (10.4\%) surpassed clozapine $(.1 \%)$ in DDD consumption and also with the cost (sulpiride $4.3 \%$ and clozapine $0.8 \%$ ).

Of the sedative-hypnotics, benzodiazepines had the highest consumption by DDD (99.8\%) compared to other sedative-hypnotics $(0.2 \%)$. Benzodiazepines also had the higher cost consumption of $99.7 \%$ compared to $0.3 \%$ of Non-Benzodiazepines. Of the Benzodiazepines, Diazepam had the highest DDD consumption of $79.6 \%$, followed by Lorazepam (17.7\%) and Midazolam $(2.5 \%)$. By cost, diazepam had the highest consumption of $94.2 \%$ respectively, then Midazolam with $4.1 \%$, and lastly lorazepam with $1.4 \%$. Hydroxyzine, the only non-benzodiazepine sedative-hypnotic accounted for $0.2 \%$ DDD and $0.3 \%$ of the total costs (Table 2). 
Table 2: Consumption of individual psychotropic agent by DDD and Cost

\begin{tabular}{|c|c|c|}
\hline \multirow[t]{2}{*}{ Psychotropic (ATC) } & \multicolumn{2}{|c|}{ Consumption of psycholeptics drugs } \\
\hline & $\mathrm{DDD}(\mathrm{mg} / \mathrm{d}, \%)$ & Cost $(\mathrm{N} \$, \%)$ \\
\hline \multicolumn{3}{|l|}{ Antidepressants } \\
\hline SSRI & $16821.7(31.6)$ & $29706.68(55.8)$ \\
\hline TCA & $36421.2(68.4)$ & $23515.48(44.2)$ \\
\hline \multicolumn{3}{|l|}{ TCA } \\
\hline Amitriptyline (N06AA09) & $3421.2(6.4)$ & $21911.9(41.2)$ \\
\hline Imipramine (N06AA02) & $33000(62.0)$ & $1603.58(3.0)$ \\
\hline \multicolumn{3}{|l|}{ SSRI } \\
\hline Fluoxetine (N06B03) & $16821.7(51.0)$ & $29706.68(55.8)$ \\
\hline \multicolumn{3}{|l|}{ Antipsychotics } \\
\hline Typical antipsychotics & $426279.1(87.5)$ & $747377.6(94.9)$ \\
\hline Atypical antipsychotics & $61166.7(12.5)$ & $40028.73(5.1)$ \\
\hline \multicolumn{3}{|l|}{ Typical } \\
\hline Chlorpromazine (N05AA01) & $363840(74.6)$ & $126,897.70(16.1)$ \\
\hline \multicolumn{3}{|l|}{ Droperidol (N05AD08) } \\
\hline Fluphenazine (N05AB02) & $3000(0.6)$ & 4,404.14 (0.6) \\
\hline Flupenthixol (N05AF01) & $525(0.1)$ & $29,230.55(3.7)$ \\
\hline Haloperidol (N05AD01) & $2070(0.4)$ & $19,203.07(2.4)$ \\
\hline Prochlorperazine (N05AB04) & $45085(9.2)$ & $538,526.50(68.4)$ \\
\hline \multicolumn{3}{|l|}{ Thioridazine (N05AC02) } \\
\hline Zuclopenthixol acetate & $8(0.0016)$ & $2,973.15(0.4)$ \\
\hline (N05AF05) & $11666.7(2.4)$ & $1,311.38(0.2)$ \\
\hline & $83.3(0.017)$ & $24,831.09(3.2)$ \\
\hline \multicolumn{3}{|l|}{ Atypical } \\
\hline \multicolumn{3}{|l|}{ Clozapine (N05AH02) } \\
\hline \multicolumn{3}{|l|}{ Sulpiride (N05AL01) } \\
\hline & $10666.7(2.2)$ & $6,372.8(0.8)$ \\
\hline & $50500(10.4)$ & $33,655.93(4.3)$ \\
\hline \multicolumn{3}{|l|}{ Anxiolytics } \\
\hline Benzodiazepines & $39565.3(99.8)$ & $770,606.30(99.7)$ \\
\hline Non-benzodiazepines & $97.3(0.2)$ & $2,052.77(0.3)$ \\
\hline \multicolumn{3}{|l|}{ Benzodiazepine } \\
\hline Diazepam (N05BA01) & $31582(79.6)$ & $727,690.40(94.2)$ \\
\hline Lorazepam (N05BA06) & $7040(17.7)$ & $11,150.63(1.4)$ \\
\hline Midazolam (N05CD08) & $943.3(2.5)$ & $31,765.22(4.1)$ \\
\hline \multicolumn{3}{|l|}{ Non-benzodiazepines } \\
\hline Hydroxyzine (N05BB01) & $97.3(0.2)$ & $2,052.77(0.3)$ \\
\hline
\end{tabular}

Total number of indications of psychotropic classes in Namibia Standard Treatment Guidelines

Table 3 shows the number of indications for the individual drugs of the psycholeptics classes according to and as indicated in the current Namibian Standard
Treatment Guidelines. Antipsychotics comprised 25.5\% of total indication, which is below antidepressants making up $31.9 \%$ of the total indications and anxiolytics which is the highest with $42.6 \%$. Figure 3 represents results of Table 3 . 
Table 3. Total number of indications of psychotropic classes in Namibia Standard Treatment Guidelines

\begin{tabular}{l} 
Psychotropic \\
\hline Antidepressants $15(31.9 \%)$ \\
\hline Antipsychotics $12(25.5 \%)$ \\
\hline Anxiolytics $20(42.6 \%)$ \\
\hline Total percent of indications of psychotropic classes in \\
STG
\end{tabular}

Figure 3. Total percent of psychotropic classes indications in Namibia Standard Treatment Guideline 
Table 4: Indications of psychotropic medicines in Namibia Standard Treatment Guidelines

\begin{tabular}{|c|c|c|}
\hline & Indication & Number of indications \\
\hline \multicolumn{3}{|l|}{ Antidepressants } \\
\hline \multirow[t]{6}{*}{ Amitriptyline } & Depressive disorder & 6 \\
\hline & Migraine headache & \\
\hline & Pain in children & \\
\hline & Neuropathic pain & \\
\hline & Post-hepatic neuralgia & \\
\hline & Varicella zoster or herpes zoster & \\
\hline \multirow{5}{*}{ Fluoxetine } & Premature ejaculation & 5 \\
\hline & Panic disorder & \\
\hline & Depression & \\
\hline & Schizophrenia & \\
\hline & Menopause & \\
\hline \multirow[t]{5}{*}{ Imipramine } & Schizophrenia & \\
\hline & Anxiety & 5 \\
\hline & Depression & \\
\hline & Panic disorder & \\
\hline & Premature ejaculation & \\
\hline \multicolumn{3}{|l|}{ Antipsychotics } \\
\hline \multirow[t]{2}{*}{ Chlorpromazine } & Schizophrenia & 2 \\
\hline & Rabies & \\
\hline Clozapine & Depression & 1 \\
\hline Droperidol & - & 0 \\
\hline Fluphenazine & Schizophrenia & 1 \\
\hline Flupenthixol & Schizophrenia & 1 \\
\hline \multirow[t]{5}{*}{ Haloperidol } & Acute Alcohol withdrawal syndrome & 5 \\
\hline & Delirium Tremens & \\
\hline & Manic Depression & \\
\hline & Schizophrenia & \\
\hline & Opioid poisoning nausea and vomiting & \\
\hline Prochlorperazine & - & 0 \\
\hline \multirow[t]{2}{*}{ Sulpiride } & Schizophrenia & 2 \\
\hline & Inadequate Lactation & \\
\hline Thioridazine & - & 0 \\
\hline Zuclopenthixol acetate & - & 0 \\
\hline \multicolumn{3}{|l|}{ Anxiolytics } \\
\hline \multirow[t]{10}{*}{ Diazepam } & Myoclonus & 11 \\
\hline & Tetanus & \\
\hline & Status epilepticus & \\
\hline & Eclampsia convulsion & \\
\hline & Muscle spasms & \\
\hline & Heat stroke & \\
\hline & Delirium & \\
\hline & Infant and children convulsions & \\
\hline & Manic episode & \\
\hline & Aggressiveness and restlessness & \\
\hline \multirow[t]{4}{*}{ Hydroxyzine } & Aggressiveness & 4 \\
\hline & Urticaria & \\
\hline & Eczema & \\
\hline & Prolonged labour & \\
\hline \multirow[t]{3}{*}{ Lorazepam } & Aggressiveness & 3 \\
\hline & Bipolar mood disorder & \\
\hline & Anxiety & \\
\hline \multirow[t]{2}{*}{ Midazolam } & Status epilepticus & 2 \\
\hline & Cardiac arrhythmia & \\
\hline
\end{tabular}

\section{Discussion}

The study set to determine the consumption of psychotropic medicines by DDD and cost in order to provide a benchmark for strategic guidance for their rational use in a LMIC setting. In this study we found the consumption of psychotropic drugs by DDDs and costs to be highest for anti-psychotics relative to antidepressants and anxiolytics. Similarly, data from the Scotland and much later with the United states of America suggest that several types of psychiatric medication, notably anti-psychotics, have consistently ranked among the costliest classes of prescription drugs in the past few years and cost has risen faster than cost of other drugs. ${ }^{26,31}$ The high consumption by DDD could be attributed to the new and increasing emergence of psychiatric disorders $^{32}$. Cost of anti-psychotics is influenced by the 
increasing number of new drugs, which as a rule are more expensive. Another factor influencing rise in antipsychotic drug cost is the prolonged life expectancy along the growing share of chronic diseases in pharmacotherapy and treatment in general ${ }^{6}$. According to the STG, anti-psychotics in total account only for $25 \%$ of indications, with schizophrenia being the common indication, compared to anxiolytics with $43 \%$ indications and anti-depressants with $32 \%$ relatively. This contravenes the increased antipsychotic consumption based on indication.

In this study we found that chlorpromazine, a typical/ first generation antipsychotic is indicated for cases with acute schizophrenia and the maintenance phase in the management of with mania, due to its pronounced sedative effects ${ }^{7}$. According to STG, chlorpromazine is an alternative to the thioxanthenes (flupenthixol) or fluphenazine if they are unavailable. Thus stock outs of flupenthixol and/or fat the facility could have attributed to increased consumption of chlorpromazine consumption by DDD) compared DDD compared to the two thioxanthenes which are costly. Haloperidol was the most costly anti-psychotic medication, accounting for up $68.4 \%$ of total expenditure. According to the DDD, Haloperidol consumed 9.2\% following Sulpiride after Chlorpromazine, however, Haloperidol is not solely indicated for schizophrenia but also indicated for the off-label use of Attention-Deficit Hyperactivity Disorder in children ${ }^{7}$ rapid sedation in acutely agitated patients ${ }^{10}$ and substance abuse including alcohol withdrawal syndrome and opioid poisoning nausea and vomiting ${ }^{7}$. Haloperidol appears to be prescribed in a wide variety of situations including, schizophrenia, bipolar disorders, Attention Deficit Hyperactivity Disorder, among others, hence the high utilization and expenditure compared to chlorpromazine, and Sulpiride. On the other hand, although droperidol, propchlorperazine, thioridazine, and zuclopenthixol acetate, were utilized at the facility, they did not appear to have any indication in the standard treatment guideline.

The anti-depressants account for the second most consumed class by DDD $(9.2 \%)$ according to the study. This finding is consistent with data from a South African stud ${ }^{11}$. Anti-depressant utilization can further be expected to increase due to increasing awareness of depression and other mental disorders among the general public, improved publication of practice guidelines to diagnose and treat depression, longer treatment course, and the development of efficient screening tools for depression in primary care. ${ }^{1,33}$ Among the antidepres- sants, imipramine was the most consumed TCA $(62 \%$ of the DDDs) and fluoxetine (51\% of DDDs) for the SSRs. SSRIs are considered to be the first choice of therapy for depressive disorders in Namibia due to a better safety profile (i.e. Smaller intrinsic toxicity) and better tolerability18. On the other hand, Tricyclic antidepressants are designated as the second choice drugs in Namibia and should be prescribed only under strict psychiatric supervision. ${ }^{34,35}$ Our findings are contrary to the recommendations of the Namibia treatment guidelines, and to other studies where low cost generic SSRIs are preferred in treatment of depressive illnesses 35 where SSRI were being consumed more than TCAs and it is therefore safe to say this is an indication of good clinical prescribing practices. Imipramine is not only indicated for depression but also schizophrenia affective disorder associated with depression, and premature ejaculation ${ }^{7}$ and this would account for its possible high DDD consumption. Fluoxetine, following closely behind Imipramine, could signify an awakening existence of quality antidepressant prescription. Amitriptyline low DDD consumption could possibly be due to its lower preference to Imipramine, with this finding being consistent with data where Imipramine pamoate group had significantly earlier rising times, and a trend toward better quality of sleep as well as better side effect profile than Amitriptyline ${ }^{7}$ Fluoxetine (SSRI), however, had the highest consumption by cost followed by Amitriptyline (TCA) appreciating an SSRI cost-effectiveness than for a TCA as seen in UK. ${ }^{19}$.

Of the anxiolytic class, Diazepam accounted for most of the group's consumption by DDD $(79.6 \%)$ and cost (94.2\%). This data is similar to Australia but contradictory for South Africa. Among the benzodiazepines prescription, more tendency to choose a drug is given to one with short half-life ${ }^{36}$ Diazepam, however, contravenes this as it has a longer half-life and is associated with abuse potential because of its rapid onset of ac$\operatorname{tion}^{28}$. An alternative is the metabolite Oxazepam which is preferred over its parent drug Diazepam due to lesser extent of causing dependence ${ }^{37}$. Due to the relative unavailability of Oxazepam, Diazepam consumption can be attributed to this as well as its many indications including heat stroke as results show. Lorazepam followed Diazepam on DDD and it has a short half-life ${ }^{38}$ which would suggest a noticeable information, and to a small extend, compliance to current prescription trends. Midazolam followed Diazepam on Cost and this was not the case in the US which found Midazolam more cost-effective than Diazepam in treatment of status epilepticus treatment ${ }^{39}$. Hydroxyzine, an antihistamine 
with sedative effects and an alternative to benzodiazepine prescription ${ }^{39}$ was the least consumed by DDD and price. As it is used as an alternative, it is less likely to be indicated for anxiety and more of its antihistaminic effect, and this could reason its consumption based on the study.

\section{Limitations}

This study is constrained by several limitations. First, data collected and obtained only included individual medicines used in this study. There might be other psycholeptics the hospital pharmacy dispenses and where therefore not included in the study as the data received was already sorted. This limited the ability to obtained representable enough data and draw more conclusions. Second, we were unable to examine a policy consumption trend analysis as data obtained presented with missing information. Example, 2009/10 did not have unit cost price and 2013/2014 drugs' strengths where absent and could not be recovered. Therefore, medicines of these financial years were omitted which is likely to lead to an underestimation and possible reduced concreteness of the findings. Third, some drugs are used for non-psychiatric purposes, such as Diazepam for heat stroke and Amitriptyline for neuropathic pain, while others are not non-psycholeptics specifically anihistamine Hydroxyzine. Nevertheless, the analysis made by the study is the first to examine consumption of psycholeptics although it does not include all the classes.

\section{Conclusions}

Psycholeptics are known for their deleterious adverse effects such as suicide for antidepressants (Fluoxetine), dependence and abuse among others, if not consumed with caution. Typical antipsychotics are more likely to cause extra-pyramidal side effects compared to the newer atypical second generation antipsychotics, and are thus preferred as first choice of therapy. Initial comparative clinical trials for atypical antipsychotics used higher doses of haloperidol to exaggerate that extrapyramidal adverse effects were higher with atypical antipsychotics. However, most anti-psychotic in the study are solely first generation indicating a lack of improvement in the quality of antipsychotic prescription despite concreted evidence. We conclude that psychiatric medications particularly newer anti-psychotics are prescribed, which is against recommendations of the Namibia Standard treatment guidelines, this contributes to the high costs associated with of anti-psychotic medication. The expenditure on psychiatric medication due use of more expensive drugs should be reduced when patients with mental health problems with low cost generics. Further research is ultimately needed to ascertain the prescribing patterns of psychiatric medication to clearly the patient level determinants. In addition mechanisms are required to curtail the prescription of psychotropic medications that are not indicated in the treatment guidelines and whose efficacy, safety, and effectiveness has not been established in the Namibian population. Therefore, there is a call for a shift towards the review of current prescribing policies and systems to promote the rational utilization of psychiatric medication.

\section{Conflict of interest}

None declared.

\section{References}

1. Patel V. Mental health in low- and middle-income countries. British Medical Bulletin. 2007.

2. World Health Organization. Improving Access to and Appropiate Use of Medicines for Mental Disorders. WHO. World Health Organization. 2017.

3. Vigo D, Thornicroft G, Atun R. Estimating the true global burden of mental illness. The Lancet Psychiatry. 2016.

4. Thornicroft G, Chatterji S, Evans-Lacko S, Gruber M, Sampson N, Aguilar-Gaxiola S, et al. Undertreatment of people with major depressive disorder in 21 countries. British Journal of Psychiatry. 2017.

5. Patel V, Saxena S, Lund C, Thornicroft G, Baingana F, Bolton P, et al. The Lancet Commission on global mental health and sustainable development. The Lancet. 2018.

6. Harvey SB, Deady M, Wang MJ, Mykletun A, Butterworth $\mathrm{P}$, Christensen $\mathrm{H}$, et al. Is the prevalence of mental illness increasing in Australia? Evidence from national health surveys and administrative data, 20012014. Med J Aust. 2017

7. Bakare K, Janik M, Dhaka P, Musese A. Mental Health Services in Namibia: Challenges and Prospects. Int J Public Ment Heal Neurosci. 2017;

8. WHO. The Global Burden of Disease: 2004 update. Update. 2008;

9. Murray CJL, Vos T, Lozano R, Naghavi M, Flaxman AD, Michaud C, et al. Disability-adjusted life years (DALYs) for 291 diseases and injuries in 21 regions, 1990-2010: A systematic analysis for the Global Burden of Disease Study 2010. Lancet. 2012;

10. Chawla S, Agarwal M, Sharma S, Jiloha RC. Drug Utilization Study of Psychotropic Drugs among Psychiatric Outpatients in a Tertiary Care Hospital. Indian J Pharm Sci. 2018; 
11. Who. Improving health systems and services for mental health. World Health. 2009;

12. Collins AM. Integrating mental health into primary care. American Journal of Nursing. 2016.

13. Hanlon C, Luitel NP, Kathree T, Murhar V, Shrivasta S, Medhin G, et al. Challenges and opportunities for implementing integrated mental health care: A district level situation analysis from five low- and middle-income countries. PLoS One. 2014;

14. Saraceno B, van Ommeren M, Batniji R, Cohen A, Gureje O, Mahoney J, et al. Barriers to improvement of mental health services in low-income and middle-income countries. Lancet. 2007.

15. Bartholomew TT. Mental Health in Namibia: Connecting Discourses on Psychological Distress, Western Treatments and Traditional Healing. Psychol Dev Soc J. 2016;

16. Ministry Of Health And Social Services. Namibia Demographic and Health Survey 2006-07. Heal San Fr. 2008;

17. Ministry of Health and Social Services. National Health Policy Framework 2010 - 2020. MoHSS. 2010.

18. World Health Organization. WHO Model List of Essential Medicines-19 ${ }^{\text {th }}$ List (April 2015). Essent Med. 2015;

19. Thakkar KB, Jain MM, Billa G, Joshi A, Khobragade AA. A drug utilization study of psychotropic drugs prescribed in the psychiatry outpatient department of a tertiary care hospital. I Clin Diagnostic Res. 2013;

20. Godman B, Kurdi A, McCabe H, Johnson CF, Barbui C, Macbride-Stewart S, et al. Ongoing initiatives within the Scottish National Health Service to affect the prescribing of selective serotonin reuptake inhibitors and their influence. J Comp Eff Res. 2019

21. Kirsch I. Antidepressants and the placebo effect. Zeitschrift fur Psychologie/Journal of Psychology. 2014.

22. McCormack J, Korownyk C. Effectiveness of antidepressants. BMJ (Online). 2018;

23. Rubio-Valera M, Beneitez I, Peñarrubia-María MT, Luciano J V., Mendive JM, McCrone P, et al. Cost-effectiveness of active monitoring versus antidepressants for major depression in primary health care: A 12-month non-randomized controlled trial (INFAP study). BMC Psychiatry. 2015;

24. Bourcier E, Korb-Savoldelli V, Hejblum G, Fernandez $C$, Hindlet P. A systematic review of regulatory and educational interventions to reduce the burden associated with the prescriptions of sedative-hypnotics in adults treated for sleep disorders. PLoS One. 2018.

25. Leucht S, Cipriani A, Spineli L, Mavridis D, Örey D, Richter F, et al. Comparative efficacy and tolerability of 15 antipsychotic drugs in schizophrenia: A multiple-treatments meta-analysis. Lancet. 2013;

26. Godman B, Leporowski A, Kibuule D, Truter I, Godman B. No Title. 2017;3(3):1-36.

27. Republic of Namibia Ministry of Health and Social Services. Namibia Essential Medicines List (Nemlist) [Internet]. Windhoek; 2015. Available from: http:// www.healthnet.org.na/Documents.html

28. Republic of Namibia Ministry of Health and Social Services. Namibia Standard Treatment Guidelines Internet]. Windhoek; 2012. Available from: http://www. healthnet.org.na/documents.html

29. WHO. WHOCC - ATC DDD Index. WHO collaborating centre for Drug statistics Methodology. 2018.

30. Ivanova EP, Truong VK, Wang JY, Berndt CC, Jones RT, Yusuf II, et al. Guidelines for ATC classification and DDD assignment. Vegetatio. 2010.

31. K M, Sabu L, Yacob M, Singh H. DRUG UTILIZATION PATTERN OF PSYCHOTROPIC DRUGS IN PSYCHIATRIC OUTPATIENT DEPARTMENT IN A TERTIARY CARE TEACHING HOSPITAL. Asian J Pharm Clin Res. 2017;

32. Häfner H. Are mental disorders increasing over time? Psychopathology. 1985;

33. Republic of Namibia Ministry of Health and Social Services. National Poily for Mental Health. Windhoek; 2005.

34. Ilyaz M, Baig MMA, Ramakrishna, Quadir MA, Fathima M, Khan SAS. Drug utilization study of antipsychotics and its common ADR'S in the psychiatry OPD of OHRC. Int J Pharm Pharm Sci. 2014;

35. Chaturvedi R, Sharma P. Drug Utilization Study of Psychotropic Drugs Prescribed in Psychiatry OPD of 1. N. Medical College associated J. K. Hospital, Bhopal district, Madhya Pradesh. I Evol Med Dent Sci. 2017;

36. Baldwin DS, Aitchison K, Bateson A, Curran HV, Davies S, Leonard B, et al. Benzodiazepines: Risks and benefits. A reconsideration. Journal of Psychopharmacology. 2013.

37. Riahi F, Tashakori A, Abdi L. Comparison between the efficacies of Risperidone with Haloperidol in the treatment of attention-deficit hyperactivity disorder (ADHD) among preschoolers: a randomized double-blind clinical trial. Electron Pbysician. 2016;

38. Greenblatt DJ, Shader RI, Franke K, Maclaughlin DS, Harmatz JS, Allen MD, et al. Pharmacokinetics and bioavailability of intravenous, intramuscular, and oral lorazepam in humans. J Pharm Sci. 1979

39. Burger J, Van der Westhuizen E, Lubbe M, Serfontein JHP. Prescribing patterns of medicine classified as "anti-depressants" in South African children and adolescents. Heal SA Gesondheid. 2009

African Health Sciences Vol 20 Issue 2, June, 2020 